\title{
Transcriptomics in human blood incubation reveals the importance of oxidative stress response in Saccharomyces cerevisiae clinical strains
}

\author{
Silvia Llopis ${ }^{1}$, Amparo Querol', Antje Heyken², Bernhard Hube ${ }^{2,3}$, Lene Jespersen ${ }^{4}$, \\ M Teresa Fernández-Espinar ${ }^{1}$ and Roberto Pérez-Torrado ${ }^{1 *}$
}

\begin{abstract}
Background: In recent years an increasing number of yeast infections in humans have been related to certain clinical isolates of Saccharomyces cerevisiae. Some clinical strains showed in vivo and in vitro virulence traits and were able to cause death in mice whereas other clinical strains were avirulent.

Results: In this work, we studied the transcriptional profiles of two S. cerevisiae clinical strains showing virulent traits and two control non-virulent strains during a blood incubation model and detected a specific transcriptional response of clinical strains. This response involves an mRNA levels increase of amino acid biosynthesis genes and especially oxidative stress related genes. We observed that the clinical strains were more resistant to reactive oxygen species in vitro. In addition, blood survival of clinical isolates was high, reaching similar levels to pathogenic Candida albicans strain. Furthermore, a virulent strain mutant in the transcription factor Yap1p, unable to grow in oxidative stress conditions, presented decreased survival levels in human blood compared with the wild type or YAP1 reconstituted strain.

Conclusions: Our data suggest that this enhanced oxidative stress response in virulent clinical isolates, presumably induced in response to oxidative burst from host defense cells, is important to increase survival in human blood and can help to infect and even produce death in mice models.
\end{abstract}

Keywords: Saccharomyces cerevisiae, Clinical strains, Transcriptomics, Blood, Oxidative stress

\section{Background}

S. cerevisiae is a ubiquitous organism that can be found in nature on plants, fruits and in soil. This species is involved in fermentative processes in beer, bread and wine, and is even consumed as a nutritional supplement, always being traditionally regarded as absolutely safe. $S$. cerevisiae and its commercially available preparations known as Saccharomyces boulardii, that are used to treat antibiotic-related diarrhea, have recently been shown to have the potential to cause a wide variety of infections, ranging from cutaneous infections and vaginitis in

\footnotetext{
* Correspondence: rober@iata.csic.es

'Instituto de Agroquímica y Tecnología de los Alimentos, IATA-CSIC, P.O. Box, 73. E-46100, Burjassot, Spain

Full list of author information is available at the end of the article
}

healthy patients to systemic infections of the bloodstream and vital organs in immunocompromised and critically ill patients [1-3]. The patients infected are mainly premature children, elderly people or patients suffering from immunosuppression due to AIDS, treatment with immunosuppressive agents, and other conditions associated with an insufficient immune response. Moreover, severe infections by $S$. cerevisiae have been occasionally reported in patients with no obvious predisposing factors $[4,5]$.

Some $S$. cerevisiae clinical strains have been isolated from blood [4,6-8]. The main routes for bloodstream infections are probably translocation of ingested yeast from the gut or direct contamination of the central venous catheter insertion site [9-11]. Similarly to other

\section{() Biomed Central}

(c) 2012 Llopis et al.; licensee BioMed Central Ltd. This is an Open Access article distributed under the terms of the Creative Commons Attribution License (http://creativecommons.org/licenses/by/2.0), which permits unrestricted use, distribution, and reproduction in any medium, provided the original work is properly cited. 
opportunistic fungal pathogens such as C. glabrata, the ability to colonize and cause disease in the host depends on the immune status of the host and the expression of certain virulence factors by the pathogen [12,13]. The majority of $S$. cerevisiae clinical isolates secrete high levels of proteases and phospholipases, can grow at $42^{\circ} \mathrm{C}$, exhibit multiple colony phenotypes, have ability to adhere to epithelial tissue and show invasive pseudohyphal growth on solid agar [9,14-16]. These studies showed that clinical isolates differed phenotypically from laboratory and wine strains in vitro, but it remains unclear whether these traits also play a role during infection. Comparison of $S$. cerevisiae clinical and nonclinical strains by molecular typing and determination of putative virulence traits has not revealed a specific virulence factor that clearly separates the strains of clinical origin from the strains of non-clinical origin $[17,18]$. In addition, little is known about the interactions between $S$. cerevisiae and host defence cells or non-cellular components [18].

mRNA level profiles of clinical strains of S. cerevisiae following exposure to whole blood rather than serum may closely reflect the in vivo response of these yeasts during bloodstream infections, since C. albicans expression profiles following intravenous infection of mice closely resembled profiles following incubation in whole blood [19], which in turn strongly correlated with the expression profile of $C$. albicans exposed to neutrophils [20]. In these studies, the authors identified differentially expressed C. albicans genes involved in general stress response, antioxidative response, the glyoxylate cycle as well as putative virulence genes expressed in response to human blood cells [19].

To better understand the physiology of virulent $S$. cerevisiae cells during infection, we performed a transcriptional analysis to investigate which genes and pathways are required for survival in blood as a model of human bloodstream infection. We compare two control nonvirulent strains with two virulent isolates (60 and D14).
These strains showed the highest levels in virulence factors, were able to colonize immunocompetent mice brain after blood infections and cause mice death, showing increased adherence ability whereas other clinical isolates showed low virulence levels $[3,18]$. Comparison of control and virulent strains revealed that amino acid biosynthesis and elevated oxidative stress response can be of special relevance for survival of $S$. cerevisiae virulent strains to host defences. Phenotypic analysis of virulent strains and a YAP1 mutant, unable to respond to oxidative stress, confirmed the importance of the increased oxidative stress response for yeast survival in human blood incubations.

\section{Results}

Transcription profile of yeasts in human blood

To obtain a global view of the $S$. cerevisiae response to blood environment and to investigate which set of genes are expressed in the different yeast, we analyzed the transcription profile of avirulent (W303 and CECT 10431) and virulent (D14 and 60) strains exposed to blood. We incubated yeast cells in human blood using the model previously established by Fradin et al. [19] and searched for significantly over-represented functional groups in upregulated (Table 1) or in the down-regulated (Table 2) set of genes during the time course of the experiment (Genes and significances are presented in Additional file 1: Table S1 and Table S2). A complete microarray dataset is presented in Aditional file 2: Table S3.

YPD precultured cells were preadapted in PBS buffer before inoculation in human blood [19]. Preadapted cell suspension was inoculated into fresh whole human blood and incubated for $0,15,30$ and $60 \mathrm{~min}$ at $37^{\circ} \mathrm{C}$. mRNA levels was determined by microarray hybridization. The arrays were hybridized with each time point and the time point $0 \mathrm{~min}$ for each strain, thus, mRNA level data for 15 , 30 and $60 \mathrm{~min}$ reflects the induction respect time 0 . Data were ratio-based normalized and a FDR of 5\% was used to identify statistically significant data. The microarray

Table 1 Significant functional groups observed in up-regulated genes after 15, 30 and 60 min of incubation in blood for virulent (60, D14) and non-virulent (CECT 10431, W303) strains ${ }^{a}$

\begin{tabular}{|c|c|c|c|c|c|c|c|c|c|c|c|c|}
\hline \multirow[t]{3}{*}{ Functional groups } & \multicolumn{12}{|c|}{ Time (min) } \\
\hline & \multicolumn{4}{|c|}{15} & \multicolumn{4}{|c|}{30} & \multicolumn{4}{|c|}{60} \\
\hline & 60 & CECT 10431 & W303 & D14 & 60 & CECT 10431 & W303 & D14 & 60 & CECT 10431 & W303 & D14 \\
\hline Translation & + & + & - & + & + & + & - & + & + & + & - & + \\
\hline Ribosome biogenesis & + & + & - & + & + & + & - & + & + & + & + & + \\
\hline Gene expression & + & + & - & + & + & - & - & + & + & + & - & + \\
\hline Amino acid biosynthetic process & + & - & - & - & + & + & - & + & + & + & - & + \\
\hline $\begin{array}{l}\text { Aspartate family amino acid } \\
\text { biosynthetic process }\end{array}$ & - & - & - & - & + & + & - & + & + & - & - & - \\
\hline Arginine biosynthetic process & - & - & - & - & + & + & - & + & + & - & - & - \\
\hline
\end{tabular}

${ }^{\mathrm{a}}$ Functional groups were $(+)$ or were not $(-)$ significantly overrepresented ( $p$-values $\left.<0.05\right)$ 
Table 2 Functional groups observed in down-regulated genes after 15, 30 and $60 \mathrm{~min}$ of incubation in blood for virulent $\left(60\right.$, D14) and non-virulent (CECT 10.431, W303) strains ${ }^{\text {a }}$

\begin{tabular}{|c|c|c|c|c|c|c|c|c|c|c|c|c|}
\hline \multirow[t]{3}{*}{ Functional groups } & \multicolumn{12}{|c|}{ Time } \\
\hline & \multicolumn{4}{|c|}{15} & \multicolumn{4}{|c|}{30} & \multicolumn{4}{|c|}{60} \\
\hline & 60 & CECT 10431 & W303 & D14 & 60 & CECT 10431 & W303 & D14 & 60 & CECT 10431 & W303 & D14 \\
\hline Protein folding & - & + & + & - & - & - & + & - & - & + & - & - \\
\hline Oxidative phosphorylation & - & - & - & - & - & + & - & - & - & + & - & - \\
\hline Glutamate biosynthetic process & - & - & - & - & - & - & - & - & - & - & - & + \\
\hline
\end{tabular}

${ }^{a}$ Functional groups were $(+)$ or were not $(-)$ significantly overrepresented ( $p$-values $\left.<0.05\right)$.

transcriptomic data presented corresponds to the average of three biological replicates including a dye swap. A complete set of data for all genes is included in Additional file 2: Table S3. Data was validated measuring mRNA levels of 7 genes by qRT-PCR in different strains and conditions (Additional file 1: Table S4) showing that inductions or repressions differ less than $20 \%$ between the two methods.

First, we searched in the data for significantly represented functional groups in up-regulated (Table 1) or in the down-regulated (Table 2) set of genes (Bonferroni corrected $p$-values $<0.05$ ). After $15 \mathrm{~min}$ of blood incubation, three functional groups (Translation, Biogenesis of ribosome and Gene expression) were found in the induced set of genes in all strains except for the laboratory strain W303. These significantly represented functional groups that comprise genes related with normal vegetative growth, appeared in the up-regulated genes during all the experiment, except time point $0 \mathrm{~min}$, indicating a continuous adaptation of these strains to the blood environment. For strain W303, the functional group Ribosome biogenesis was significant only after 60 min of incubation, revealing a delayed adaptation to the new environment. Strains CECT 10431, 60 and D14 showed no differences in this set of functional groups. Genes belonging to these functional groups include ribosomal protein genes such as RPL32 and RPS10, translational elongation factor genes such as TEF2 and EFB1, and tRNA synthetase genes such as THS1.

The functional group Amino acid biosynthetic process was observed in strain 60 at time point $15 \mathrm{~min}$ and in strains 60, D14 and CECT 10431 after 30 and $60 \mathrm{~min}$. Furthermore, the functional groups Aspartate family amino acid biosynthetic process and Arginine biosynthetic process were significant for strain 60, D14 and CECT 10431 at $30 \mathrm{~min}$ and for strain 60 at the last time point $(60 \mathrm{~min})$.

Some functional groups were found to be significantly repressed (Table 2). Protein folding was observed in CECT 10431 after 15 min of incubation and during the entire time course in W303, but not in the virulent strains 60 and 14. The main function of the genes included in this group, such as SSA2, is to encode molecular chaperones, which bind newly-translated proteins to assist proper folding and to prevent aggregation/misfolding [21]. The down regulation of genes of this functional group in W303 is consistent with the observed delay in the functional groups related to preparation for growth like Ribosome biogenesis. In the down-regulated set of genes, the functional group Oxidative phosphorylation was observed in strain CECT 10431 after 30 and $60 \mathrm{~min}$ and the functional group Biosynthesis of glutamate was detected at $60 \mathrm{~min}$. No significant functional group was observed in the down-regulated genes in virulent strains 60 and D14.

On the other hand, we found significant changes in the mRNA levels of specific genes implicated in important biological process (see Additional file 2: Table S3). At the early stage $(15 \mathrm{~min})$, several genes encoding glycolytic enzymes were up-regulated. The genes encoding glucose-6-phosphate isomerase (PGI1), phosphofructokinase $(P F K 2)$ and aldolase (FBA1) were up-regulated at early stages of incubation, but the mRNA levels were even higher after $30 \mathrm{~min}$ and $60 \mathrm{~min}$ for wine strain CECT 10431 and D14 respectively. For strain 60, the maximal mRNA level was monitored after $60 \mathrm{~min}$. For the laboratory strain W303, the mRNA level of all three genes was down-regulated at $15 \mathrm{~min}$, PGI1 was weakly induced at $30 \mathrm{~min}$, and PFK2 mRNA level was upregulated at $60 \mathrm{~min}$. In strain 60 , other genes that encode glycolytic enzymes were mostly down-regulated in the early stages compared to 0 min time point, but transcripts were considerably elevated at the later stages of the incubation, such as, glyceraldehyde 3-phosphate dehydrogenase (TDH3), phosphoglycerate kinase (PGK1) and enolase (ENO1). Also, the mRNA level of gluconeogenic enzyme phosphoenolpyruvate carboxykinase (PCK1) was strongly down-regulated in this strain.

The genes encoding the key enzymes of the glyoxylate cycle, isocitrate lyase (ICL1) and malate synthase (MLS1) were down-regulated in all strains during the time course of the experiment, although this repression was less strong at the later stage in strains D14 and 60. These genes are subjected to catabolite repression which suggests that yeast cells have access to glucose during all the experiment. 


\section{Comparison of mRNA levels between virulent and non- virulent strains in human blood}

To identify genes specifically expressed in S. cerevisiae virulent isolates in blood, we analyzed the mRNA levels at different incubation times and we identified statistically significant data when comparing average of virulent strains group (60 and D14) data with average of nonvirulent group (W303 and CECT 10431) data. Then we searched for functional groups of genes whose mRNA level was specifically associated with virulent strains of S. cerevisiae (Table 3).

After $15 \mathrm{~min}$ of blood incubation, three functional groups were significantly overrepresented in the upregulated set of genes in virulent strains compared to non-virulent strains: Vacuole organization, Xenobiotic transporter and Base-excision repair. The functional group Vacuole organization, induced again after $30 \mathrm{~min}$, includes genes related with biogenesis, protein-vacuolar targeting and vacuole fusion (CUP5, VPS3 and VTC1). The Base-excision repair pathway removes lesions that result from exposure to endogenous or exogenous reactive oxygen species (ROS) [22] and includes genes such as POL30 (DNA polymerase processivity factor), RAD27 (5' flap endonuclease), APN1 (DNA apurinic or apyrimidinic site lyase) and OGG1 (purine-specific oxidized base lesion DNA N-glycosylase). The level of mRNA of these genes decreased along the experiment in virulent strains.

Seven functional groups more were enhanced at time points 30 or $60 \mathrm{~min}$ in virulent strains. Four closely related groups (Amino acid biosynthetic process, Amino acid metabolic process, Amine biosynthetic process and Nitrogen compound biosynthetic process) include genes that take part in the biosynthesis of some aminoacids, such as aromatic aminoacids (ARO3, ARO4), histidine (HIS1, HIS5), arginine (ARG1, ARG5, ARG6, ARG8), tryptophan (TRP3), lysine (LYS1, LYS4), leucine (LEU9), and serine (SER3, SER33). We wanted to know if the presence of several auxotrophies in the laboratory strain W303 could indirectly affect the appearance of functional groups related to aminoacid metabolism in this analysis. We repeated the data analysis comparing the two virulent strains (D14 and 60) against the wine strain CECT 10431, excluding W303 strain. The results showed once again the appearance of aminoacid metabolism functional groups as Cellular aminoacid metabolic process, containing similar genes as (LEU9, SER3, ARG1, $A R G 8)$. Then we concluded that W303 auxotrophies are not biasing the results, probably because the short time sampling, and that aminoacid metabolism related genes are highly activated in the clinical isolates. The fifth functional group, Phosphatase activity, includes genes such as PHO3, PHO5 and PHO12 that are expressed under low-phosphate conditions. It may indicate a response to phosphate starvation during blood incubation. Also, PHO3 is able to hydrolyze thiamin phosphates in the periplasmic space, increasing cellular thiamine uptake. Another functional group is Transmembrane transporter activity which includes genes that take part in the mitochondrial transport (CTP1, YHM1), zinc transport (ZRT1) and amino acid transport (GNP1).

A key functional group, Cell redox homeostasis, was found to be enhanced during the incubation in blood in virulent strains. The genes belonging to this group help to maintain a reduced environment in the cell and are associated with virulence in bacteria [23-25]. These genes play a significant role in defending the

Table 3 Functional groups observed in up-regulated genes in virulent strains related to control strains after 15, 30 and 60 min of incubation in blood ${ }^{a}$

\begin{tabular}{|c|c|c|c|c|}
\hline \multirow[t]{2}{*}{ Functional groups } & \multicolumn{3}{|c|}{ Time (min) } & \multirow[t]{2}{*}{ Genes } \\
\hline & 15 & 30 & 60 & \\
\hline Base-excision repair & + & - & - & POL30, POL31, RAD27, APN1, OGG1 \\
\hline Vacuole organization & + & + & - & $\begin{array}{l}\text { CMD1, VPS3, CUP5, VTC1, SFK1, VID24/MD1/ VPS45/ TRX2/ TRX1/VAC7/ TPM1/ } \\
\text { VTC3/ }\end{array}$ \\
\hline Xenobiotic transporter & + & - & - & PDR5, SNQ2, PDR12 \\
\hline $\begin{array}{l}\text { Amino acid biosynthetic process/ Amine biosynthetic } \\
\text { process/ Nitrogen compound biosynthetic process }\end{array}$ & - & + & + & $\begin{array}{l}\text { ARO4/ ARO3/LYS4/ HIS1/ ARG5/ARG6/SER3/ILV1/ SER33/ HIS5/LYS1/TRP3/ } \\
\text { ARG1/ARG8/LEU9/ORT1/ SAM4 }\end{array}$ \\
\hline Amino acid metabolic process & - & + & + & $\begin{array}{l}\text { ADH5/ ARO4/ ARO3/LYS4/ HIS1/ ARG5/ARG6/SER3/ILV1/ADH4/ SER33/ HIS5/ } \\
\text { LYS1/ URA2/ TRP3/MSE1/ ARG1/ ARG8/LEU9/ ORT1/ SAM4/ }\end{array}$ \\
\hline Phosphatase activity & - & + & + & $\begin{array}{l}\text { PTC3/ PHO3/ PHO5/ DPP1/ LPP1/ SDT1/ PHO12/ INP51/ SAP185/ SAC1/ PPZ1/ } \\
\text { TSL1/ YMR087WTPS3/ FCP1/ YNL217W/ PHO12 }\end{array}$ \\
\hline Transmembrane transporter activity & - & + & - & $\begin{array}{l}\text { CTP1/ GGC1/ ATP17/ GNP1/ PIC2/ HXT10/ VPS73/ ZRT1/ TPO2/ TNA1/ AVT1/ } \\
\text { VMA5/ ZRT3/ YBT1/ AQY2/ SMF3/ ZRT2/ ATR1/ ITR2/ ORT1/ ODC2/ PDR12/ } \\
\text { YMC1/ ANT1/ TPO3/ }\end{array}$ \\
\hline Cell redox homeostasis & - & - & + & $\begin{array}{l}\text { TTR1/ TRX2/ TRX1/ TSA1/ GLR1/ YNL134C/TPS1/ PGM2/ GRE2/ MXR1/ PDI1/ } \\
\text { UBA1/ LYS20/ AHP1/ TKL1/TAL1/ADH6/ CYS3 }\end{array}$ \\
\hline
\end{tabular}

\footnotetext{
${ }^{a}$ Functional groups were $(+)$ or were not $(-)$ significantly overrepresented ( $p$-values $\left.<0.05\right)$.
} 
cell against oxidative stress exerted by reactive oxygen species (ROS), integral effectors of mammalian host defenses. Stimulated leucocytes can be a source of ROS, which may cause oxidative stress. Defense against this stress seems to be enhanced at $60 \mathrm{~min}$ of incubation of blood. Indeed, when we observed oxidative stress related genes, most of them (17) show statistically significant higher levels in virulent strains compared to non-virulent strains (Figure 1). On average, a very significant $(p<0.005)$ increase $(0.20$ to 1.43$)$ is observed in the virulent strains respect to non-virulent strains. Interestingly, all the 17 genes are regulated by Yap1p, the main regulator of oxidative stress in yeasts (http://www.yeastract.com). Several components of the thioredoxin system are included in this set of genes. A thioredoxin peroxidase (TSA1) and two thioredoxin genes (TRX1 and TRX2) were strongly upregulated in virulent strains at time $60 \mathrm{~min}$. Also mRNA levels of $T R R 1$, a thioredoxin-disulfide reductase gene, increase during the incubation in blood in strains 60 and D14.

Only the Pyridoxine metabolic process functional group was downregulated with regards to non-virulent strains at time point $30 \mathrm{~min}$. This group includes genes $(S N Z, S N O 2)$ involved in pyridoxine metabolism and thiamine biosynthesis.

\section{Resistance to oxidative stress of virulent and non-virulent strains}

To confirm the relevance of the oxidative stress response on the virulent nature of yeast strains we measured the percentage of survival of these four strains after one hour in the presence of elevated levels $(6 \mathrm{mM})$ of $\mathrm{H}_{2} \mathrm{O}_{2}$ (Figure 2). Virulent isolates exhibited higher survival rates whereas W303 and CECT 10431 showed very low survival. Statistical analysis confirmed significant differences in oxidative stress between virulent and non-virulent strains $(\mathrm{p}<0.0005)$ whereas no significant differences between CECT 10431 and W303 or 60 and D14 were found (Additional file 1: Table S5).

\section{Survival of yeast strains in human blood}

The aim of this experiment was to study the survival of control and pathogenic S. cerevisiae strains comparing them with $C$. albicans and also to know which blood cell types are affecting more yeast self-preservation. In this experiment $S$. boulardii strain Ultralevure, a biotherapeutic agent which has been described as a potential pathogenic $[6,9,10]$, was included. To investigate the survival of the different strains, we incubated the cells $10 \mathrm{~min}$ and 1 hour at $37^{\circ} \mathrm{C}$ in human blood (Table 4).

We observed that after $10 \mathrm{~min}$ the virulent strains D14 and 60 showed survival levels similar to the pathogenic C. albicans strain SC5314. In contrast, control strain W303 presented significantly lower survival. After $60 \mathrm{~min}$ of incubation the survival of all strains decreased. However we observed again a similar pattern since strains 60 and D14 showed comparable values to virulent SC5314 whereas W303 presented significantly lower survival. $S$. boulardii strain showed similar values to the $C$. albicans strain in this assay. The wine strain

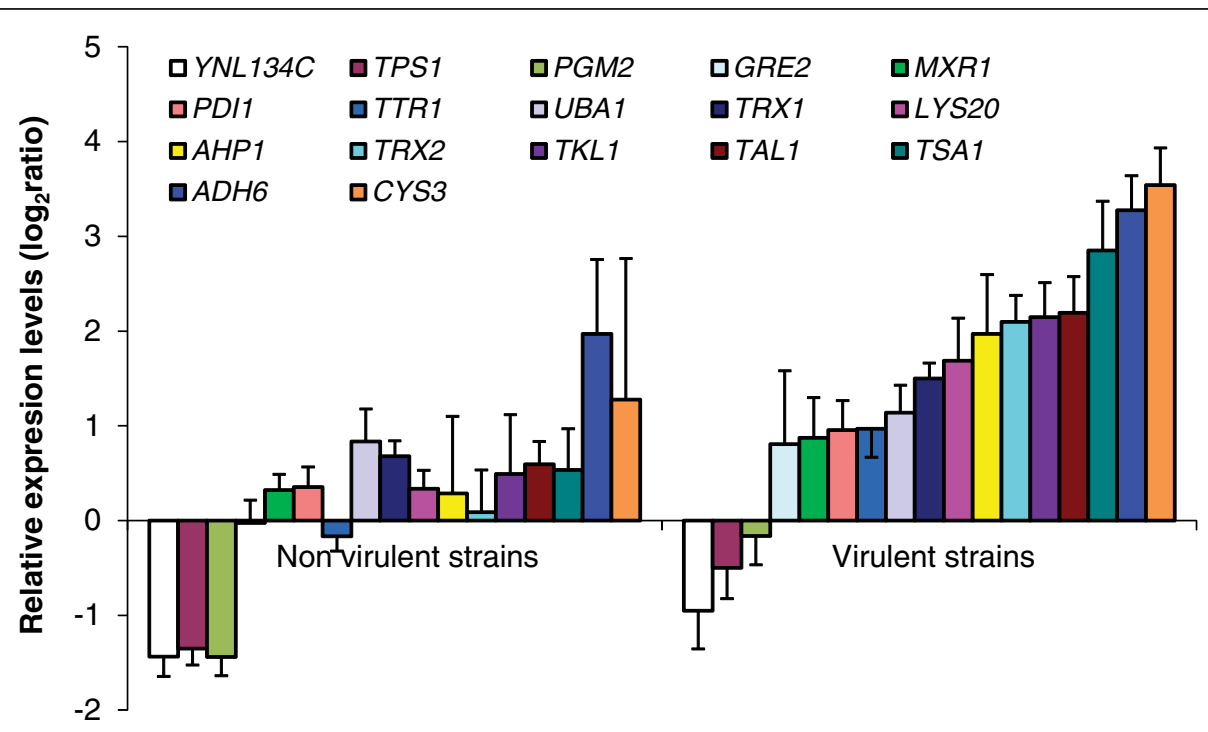

Figure 1 Expression levels of oxidative stress related genes comparing virulent and non-virulent strains after 60 min of incubation in human blood. Induction of oxidative stress related genes in non-virulent (CECT 10431 and W303) or virulent strains (D14 and 60) was averaged. All genes showed significantly different $(p<0.05)$ values between the two groups using Student's t-test statistical analysis. Average and standard errors 6 are shown. 


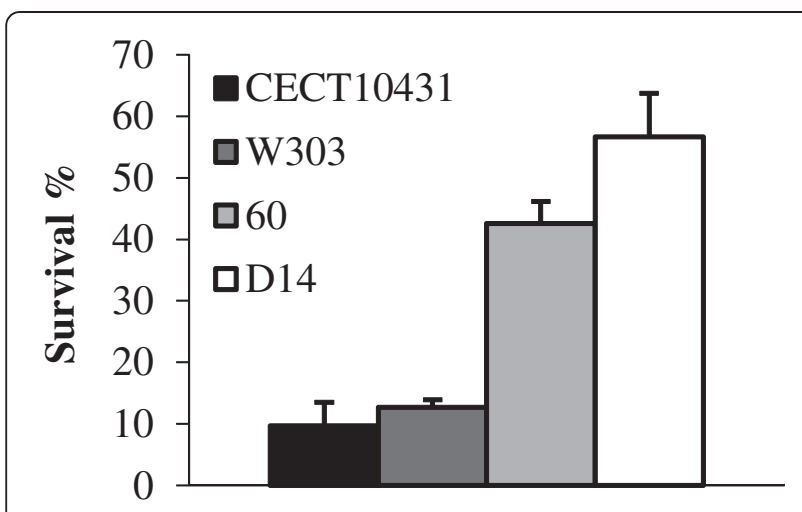

Figure 2 Survival percentages comparison of virulent and nonvirulent strains after oxidative stress. The different strains were exposed to $6 \mathrm{mM} \mathrm{H}_{2} \mathrm{O}_{2}$ for 1 hour and then plated in YPD media for colony counting. Percentages were calculated comparing with untreated cells. Averages and standard errors of independent triplicates are shown.

CECT10431 also presented survival levels lower than $C$. albicans and virulent $S$. cerevisiae strains but data was not significant.

\section{A virulent strain mutant in Yap1p showed decreased survival in human blood}

To confirm that oxidative stress response of virulent strains is important to survive in human blood we decided to study performance of a strain unable to grow in oxidative stress conditions. Since all genes with increased mRNA levels in virulent strains observed in Figure 1 are regulated by the transcription factor Yap1p, we decided to study survival in human blood comparing the wild type strain D14 with a homozygous for a $\Delta$ yap1 mutation. First we confirmed that D14 $\Delta$ yap1 was unable to survive in the presence of oxidative stress conditions ( $2.5 \mathrm{mM} \mathrm{H}_{2} \mathrm{O}_{2}$ ) whereas the wild type strain presented no growth defects (Figure 3A). Reincorporation of YAP1 in D14YAP1 strain reverted this phenotype. This experiment confirmed that Yap1p is essential to perform a proper oxidative stress response in virulent strains. Then we evaluated the behavior of the D14 $\Delta$ yap1 strain in human blood incubation assay. Using the same conditions described above, yeast cells were added to blood and survival was determined after 0, 30, 60 and $90 \mathrm{~min}$ (Figure 3B). The results showed that D14 $\triangle$ yap1 survival decreased significantly ( $p$-value $<0.05$ at 30 or 60 and $p$-value $<0.01$ at $90 \mathrm{~min}$ time points) reaching a level comparable to that of the laboratory strain W303 at $60 \mathrm{~min}$ (Table 4), confirming the relevance of a proper oxidative stress response to survive in human blood. Again, D14YAP1 showed similar phenotype than the wild type, confirming the involvement of Yap1p in blood survival.

\section{Discussion}

Blood is a complex milieu composed of several types of immunoactive cells and molecules. As we have previously observed, several clinical strains of $S$. cerevisiae adapt to blood environment and are able to survive and spread to other tissues in murine models. To better understand the response of S. cerevisiae to this complex environment and to search for special features of virulent strains we have analysed the transcriptome of $S$. cerevisiae cells after contact with human blood. The results showed that they express several groups of genes in order to rapidly accommodate to this special environment. As expected, a high mRNA level of genes encoding factors involved in protein synthesis were detected in every strain after 15 min inoculation in blood, except for the laboratory strain W303. The strong induction of these set of genes is probably a consequence of the yeast cells transfer from nutrient poor medium (PBS) to a relatively nutrient-rich medium (blood). The downregulation of $P C K 1$, encoding the gluconeogenic enzyme phosphoenolpyruvate carboxykinase, and other genes supports that yeast cells are exposed to a carbohydraterich environment, even at the later stages of incubation in blood, when most of the yeast cells are phagocytized. In C. albicans, a high level of different transcripts involved in protein synthesis was also detected at the beginning of the incubation in blood, but the mRNA level of these genes decreased during the incubation [19], indicating that growth initiation occurred only in the early stages. This suggests that $C$. albicans has a faster response to adapt to blood environment than S. cerevisiae.

We observed that the induction of genes involved in aminoacid biosynthetic pathway is present during the middle and the later time course in the virulent strains, while in non-virulent strains they appear later or don't appear. Also, following exposure to human neutrophils

Table 4 Yeasts survival in human blood incubations a

\begin{tabular}{lllllll}
\hline $\begin{array}{l}\text { Species } \\
\text { Strain }\end{array}$ & $\begin{array}{l}\text { C. albicans } \\
\text { SC5314 }\end{array}$ & $\begin{array}{l}\text { S. cerevisiae } \\
\mathbf{6 0}\end{array}$ & $\begin{array}{l}\text { S. cerevisiae } \\
\text { D14 }\end{array}$ & $\begin{array}{l}\text { S. boulardii } \\
\text { Ultralevure }\end{array}$ & $\begin{array}{l}\text { S. cerevisiae } \\
\text { CECT 10431 }\end{array}$ & $\begin{array}{l}\text { S. cerevisiae } \\
\text { W303 }\end{array}$ \\
\hline Time (min) & & & & & & \\
10 & $87.4 \pm 8.7$ & $98.8 \pm 8.7$ & $76.5 \pm 13.8$ & $76.0 \pm 13.8$ & - & $66.0 \pm 11.2^{*}$ \\
60 & $56.4 \pm 3.7$ & $56.4 \pm 3.7$ & $60.5 \pm 5.8$ & $60.0 \pm 5.8$ & $50.8 \pm 9.8$ & $35.7 \pm 4.8^{*}$ \\
\hline
\end{tabular}

${ }^{a}$ Survival is expressed as\% of cfu respect time $0 .{ }^{*}$ Strains individually compared to C. albicans SC5314 strain presented $p<0.05$. 

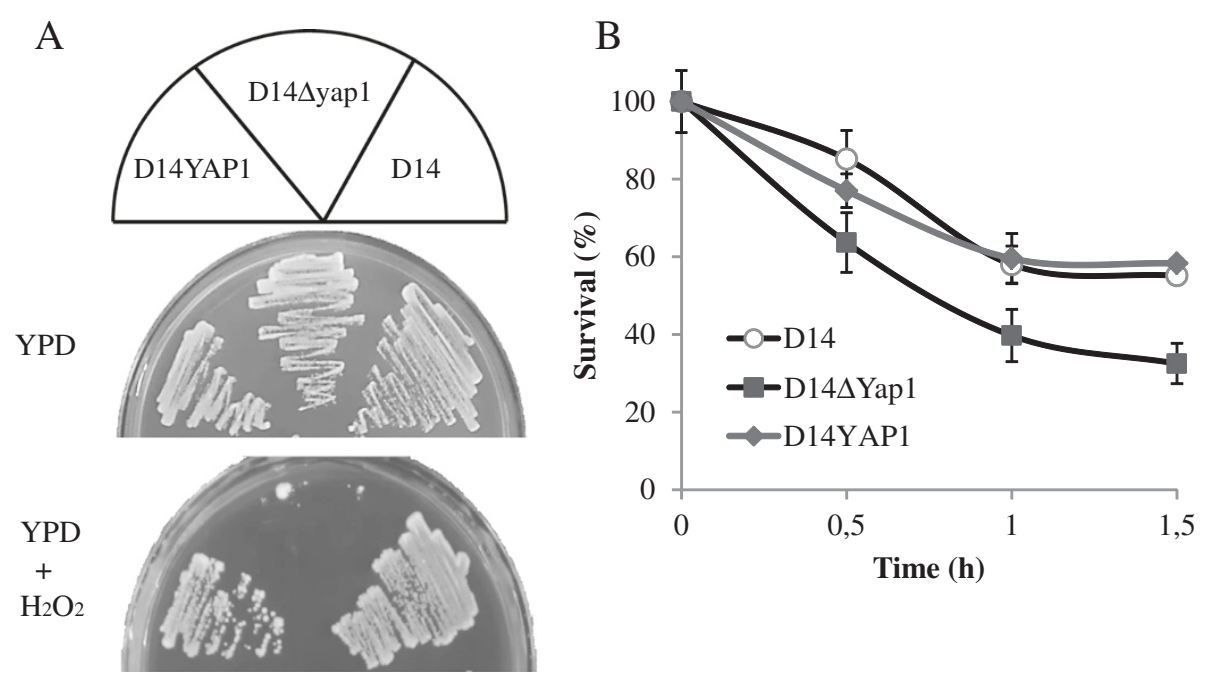

Figure $\mathbf{3}$ Implication of Yap1p transcription factor in human blood yeast survival. In panel $\mathbf{A}$, the strain D14 and a YAP1 mutant were plated in YPD or YPD with $2.5 \mathrm{mM} \mathrm{H}_{2} \mathrm{O}_{2}$. In panel $\mathbf{B}$, blood survival assay is shown for wild type D14 and YAP1 mutant strain. Yeasts were inoculated 1:1 ratio respect leucocytes and yeast survival was followed for 1.5 hours by plating in YPD agar plates. Data corresponds to average and standard errors of three independent biological replicates.

or cultured macrophages, C. albicans populations upregulate amino acid biosynthetic genes [20,26]. RubinBejerano et al. [26] observed an induction of these pathways after yeast cells were ingested by neutrophils, but it was not present when yeast cells were ingested by human monocytes. It may suggest that the microenvironment in the phagosome inside the neutrophil is deficient in amino acids and it generates a rapid response from the virulent $S$. cerevisiae strains. However, non-virulent strains are slower or less efficient in the adaptation to this microenvironment, decreasing their possibilities to survive. In addition, the methionine and arginine biosynthetic genes are not induced when S. cerevisiae is phagocytized by the murine macrophage-like cell line J774A [27]. Additionally, Kingsbury et al. [28] revealed the relevance of amino acid biosynthesis for yeast survival in murine host; however processes important for sensing and responding to quality and concentration of nitrogen compounds were not required for yeast survival in vivo, indicating that yeast can use a variety of nitrogen sources in these conditions. The pyridoxine metabolic process genes were downregulated in the virulent strains with regards to non-virulent strains. Padilla et al. [29] observed that these genes were expressed under nutrient limitation, so it may reflect that strains 60 and D14 were not exposed to a limitation of specific nutrients, such as nitrogen.

The glyoxylate cycle is induced upon phagocytes ingestion of the bacteria Mycobacterium tuberculosis [30] and other fungi such as C. neoformans [31], C. albicans [27], Leptosphaeria maculans [32] and S. cerevisiae [27]. This shift in metabolism has been interpreted as a response to the glucose-poor environment of the macrophage, and the ability to make that shift appears to contribute to the virulence of some pathogens. However, in our condition using complex blood medium, the genes encoding the principal enzymes of the glyoxylate cycle, isocitrate lyase (ICL1) and malate synthase (MLS1), were downregulated during the time course, although this repression was less strong at the later stage in strains D14 and 60 . This suggests that yeast cells have access to glucose during almost all the experiment. The fact that icl1s mutants were only slightly deficient in vivo [33] suggests that the glyoxylate cycle has a minor contribution to S. cerevisiae fitness in vivo. The ICL1 gene of both $S$. cerevisiae and $C$. albicans has recently been shown to be substantially induced upon exposure to macrophages in vitro [27,34]. However, these experiments were performed with murine macrophages in cell culture medium, where glucose concentration may be different from blood. Furthermore, a C. albicans icl1 $\Delta /$ icl1 $\Delta$ mutant showed a substantial reduction in virulence [27], while the same mutant was not attenuated in survival in blood [20], suggesting that the ICL1 gene may play a general role when C. albicans has left the bloodstream. All these data suggest that the ICL1 gene may play also a general role in S. cerevisiae in human infections but after yeast cells has left the bloodstream.

When we compared the transcriptomes of virulent and control strains, we observed several specific groups of genes that may explain the pathogenic nature of the virulent strains. An interesting functional group of upregulated genes during blood incubation was Cell redox homeostasis. We confirmed that this increased oxidative 
stress response correlates with phenotypical advantage of virulent strains in pro-oxidant environments since they have significantly much higher survival in the presence of high concentrations of $\mathrm{H}_{2} \mathrm{O}_{2}$. Furthermore, they survive to oxidative burst attack from blood cells significantly better than control strain W303 and at similar levels that pathogenic C. albicans. The decreased survival of YAP1 mutant strain in human blood incubations highlights the importance of the genes included in the Yap1p regulon in determining the virulence of S. cerevisiae strains.

Since we have used a molecular transcriptomic approach and human blood media, it was difficult to use several virulent and non-virulent strains, in order to obtain a broad comparative view. However, Diezmann and Dietrich [35] compared hundreds of clinical isolates due to the use of easy tractable phenotypical assays. In concordance with our results, Diezmann and Dietrich [35] showed that $S$. cerevisiae clinical isolates were more resistant to oxidative stress. This data suggest a correlation between survival in oxidative stress and yeast pathogenicity and strongly supports our data. Macrophages, neutrophils and other phagocytic cells generate potent reactive oxygen and nitrogen species (ROS and RNS), which are toxic to most fungal pathogens, causing damage to DNA, proteins and lipids [36]. Fungal pathogens display different degrees of resistance to the reactive oxygen and nitrogen species used by human cells to counteract infection [37]. Fungal resistance to ROS offers protection from oxidative host defenses and is undoubtedly an advantageous pathobiological property $[38,39]$. It is worth mentioning that several genes belonging to the thioredoxin system were upregulated, which suggests its implication in yeast defense against blood defenses. Indeed, the thioredoxin system of $C$. albicans has been shown to be expressed during growth in human blood or mucosal tissue $[19,20,40]$, indicating that ability to respond to oxidative stress might be crucial in the early stages of systemic $C$. albicans infections. Also, TRX1 is necessary for survival of C. neoformans in the oxidative environment of macrophages and important for virulence of this fungal pathogen [41]. TSA2 and GPX2 genes have been shown to be induced in S. cerevisiae strains when exposed to neutrophils [26], and a clear antioxidant response has been observed. Fradin et al. [20] demonstrated that neutrophils play a key role in bloodstream infections with C. albicans. This observation is in line with the high susceptibility of neutropenic patients (deficient in these immune cells) to disseminated candidiasis $[42,43]$.

In conclusion, this work supports the view that oxidative stress response of $S$. cerevisiae strains has a special importance for survival in blood, having a high impact in determining their virulence. This characteristic can help these yeasts to prevail in immunocompromised patients and cause systemic infections.

\section{Conclusions}

In the present work we have found significant differences at molecular level between $S$. cerevisiae nonvirulent strains and virulent clinical strains with remarkable capabilities of infect and even produce mice death. Transcription analysis in blood incubations pointed out an enhanced oxidative stress response of virulent strains that is reflected in an increased ability to survive in the presence of high concentrations of the oxidant $\mathrm{H}_{2} \mathrm{O}_{2}$. Indeed, they are able to survive to a similar extent than pathogenic C. albicans strain in blood incubations. These data suggest that $S$. cerevisiae virulent strains are able to extend the survival after the macrophage oxidative burst attack, having more chances to persist and perform systemic infections.

\section{Methods}

\section{Strains and media}

Several S. cerevisiae isolates were used in this work: a clinical isolate from vagina (isolate 60) [7], a brewer's strain isolated from a commercial nutritional complement product (D14) [18], and two control strains: (one laboratory strain W303 (MATa; ura3-52; $\operatorname{trp} 1 \Delta 2$; leu23,112; his3-11; ade2-1; can1-100) and a wine strain CECT 10431) [18]. Isolate 60 and D14 were chosen from a virulent yeast collection obtained from several sources because they have the highest levels in virulence factors and because they were able to survive and colonize the brain of immunocompetent mice after blood infections and cause mice death, showing increased adherence ability $[3,18]$. Also, they were phagocytosed by macrophages with less efficiency than CECT 10431 [18]. The natural wine strain CECT 10431 was used as negative control because it is unable to proliferate in any organ after its intravenous inoculation in murine systems $[3,18]$. Saccharomyces cerevisiae var. boulardii commercial preparations also known as Ultralevure were used in blood survival experiments. C. albicans SC5314 [44] was used as a positive control yeast in blood incubations. S. cerevisiae and C. albicans strains were cultured in YPD medium (1.0\% yeast extract, $1.0 \%$ Bacto-peptone and $2.0 \%$ glucose) prior to blood incubations.

The mutant D14 $\Delta$ yap1 strain was obtained using a PCR-based gene-replacement strategy using a deletion cassette containing geneticin resistance amplified from pUG6 plasmid [44]. The primers used are included in the Additional file 1: Table S6. These primers had between 40 homologous bases to the ends of the gene coding sequence. The amplified PCR product was used for yeast modification by homologous recombination following yeast transformation using the lithium acetate 
procedure. PCR reactions using plasmid pUG6 as template were as follows: $2 \mathrm{~min}$ at $94^{\circ} \mathrm{C}$; 30 cycles of $15 \mathrm{~s}$ at $94^{\circ} \mathrm{C}, 30 \mathrm{~s}$ at $50^{\circ} \mathrm{C}, 2 \mathrm{~min}$ at $72^{\circ} \mathrm{C}$ and $5 \mathrm{~min}$ at $72^{\circ} \mathrm{C}$. Cells were transformed with the PCR product using the LiAc protocol (http://home.cc.umanitoba.ca/ gietz/). After heat shock, cells were incubated for 3 hours in YPD liquid medium at $30^{\circ} \mathrm{C}$. Finally, transformed cells were selected on YPD plates with geneticin $(200 \mathrm{mg} / \mathrm{L})$. Geneticin resistance was removed by transforming with pSH47, a plasmid containing Cre recombinase, inducing in galactose for $24 \mathrm{~h}$ and selecting colonies without geneticin resistance. Since D14 strain is diploid, the second YAP1 gene deletion was performed with the same procedure but using a replacement cassette containing hygromycin B resistance amplified from pAG32 plasmid [45]. The YAP1 gene deletion was confirmed by PCR analysis and resistance to $\mathrm{H}_{2} \mathrm{O}_{2}$. The strain D14YAP1 was obtained by transforming D14 $\Delta$ yap1 strain with a plasmid containing a wild type copy of YAP1 (pYAP1) and selecting in YPD with $200 \mu \mathrm{g} / \mathrm{mL}$ of G418 (Sigma). The plasmid obtained from Kuge et al. [46] was marker swapped for KANMX by homologous recombination using a cassette obtained by PCR and using pUG6 plasmid as a template.

\section{Human blood incubations}

Yeast cells were precultured overnight in YPD medium at $30^{\circ} \mathrm{C}$. Cells were counted and preadapted in PBS buffer at a density of $2.5 \times 10^{9}$ cells $/ \mathrm{ml}$ (corresponding to two cells per leukocyte) incubating $30 \mathrm{~min}$ at $37^{\circ} \mathrm{C}$ before inoculation in human blood [22]. Human peripheral venous blood was obtained with signed informed consent under protocols approved by the bioethics commission of Centro Superior de Investigaciones Científicas. Human peripheral venous blood was collected from healthy volunteers by venipuncture using ammonium heparin syringes (Monovette ${ }^{\circledR}$, Sarstedt). Preadapted cell suspension $(100 \mu \mathrm{l})$ was inoculated into $25 \mathrm{ml}$ of fresh whole human blood and incubated for 0, 15, 30 and $60 \mathrm{~min}$ at $37^{\circ} \mathrm{C}$ in semi-aerated cultivation flasks. At each time point, 2 volumes of $0.5 \%$ Triton X-100 were added to break blood cells. Then the cells and blood cells debris were collected by centrifugation at $1300 \mathrm{x} \mathrm{g}$ for $3 \mathrm{~min}$ at $4^{\circ} \mathrm{C}$. The pellet with yeast and blood cells debris was transferred to a tube with $1 \mathrm{ml}$ of cold water. In order to separate yeast cells, a fast centrifugation pulse (70 x g for 15 seconds) was performed. This treatment precipitated blood cells debris maintaining only yeast cells in the supernatant. This supernatant was centrifuged at $1300 \mathrm{x} \mathrm{g}$ for 2 minutes at $4^{\circ} \mathrm{C}$ and the resulting pellet was immediately frozen in liquid nitrogen. Control samples (time point 0 ) were treated exactly the same way as the other samples to exclude variations due sample manipulation in the transcriptomic data.

\section{RNA extraction and labeling}

Frozen cells were lysed and homogenized by vortexing in LETS buffer (10 mM Tris $\mathrm{pH} 7.4,10 \mathrm{mM}$ lithiumEDTA, $100 \mathrm{mM}$ lithium chloride, 1.0\% lithium lauryl sulfate) with acid-washed glass beads $(0.4-0.6 \mathrm{~mm}$; Sigma-Aldrich) for $3 \mathrm{~min}$, and total RNA was extracted using phenol:chloroform RNA method [47]. mRNA was amplified using Low RNA Input Fluorescent Linear Amplification Kit (Agilent Technologies) according to the manufacturer's instructions. The amplification is divided in two steps: a first step to synthesize cDNA using oligo (dT) primer and a second step to synthesize cRNA. The amplified cRNA obtained was purified using RNeasy kit (Qiagen) following the instructions. cDNA for transcriptional profiling was produced by incubating $1.5 \mu \mathrm{g}(16.5 \mu \mathrm{l})$ amplified cRNA with $1 \mu \mathrm{l}(0.4 \mu \mathrm{g} / \mu \mathrm{l})$ random hexamers (Agilent) at $70^{\circ} \mathrm{C}$ for $5 \mathrm{~min}$. After adding $1 \mathrm{x}$ first strand buffer, $12 \mathrm{mM}$ DTT, $500 \mu \mathrm{M}$ dATP, $500 \mu \mathrm{M}$ dCTP, $500 \mu \mathrm{M}$ dGTP, $160 \mu \mathrm{M}$ dTTP (Fermentas), $330 \mu \mathrm{M}$ aminoallyl- dUTP (Fermentas), $10 \mathrm{U}$ ribonuclease inhibitor (Invitrogen) and $400 \mathrm{U}$ SuperScript III reverse transcriptase (Invitrogen) the mix was incubated for 16 hours at $50^{\circ} \mathrm{C}$. cDNA obtained was purified using MinElute PCR Purification kit (Qiagen). Labeling reaction was produced incubating 1.5-2 $\mu \mathrm{g}$ of aminoallyl-cDNA with $3 \mu \mathrm{l}$ of Cy3 and Cy5 fluorophores (Amersham) at basic $\mathrm{pH}\left(0.2 \mathrm{M} \mathrm{Na} \mathrm{CO}_{3}, \mathrm{pH}\right.$ 9) for 2 hours at room temperature. Labeled cDNA was purified using the same kit mentioned above.

\section{Microarray hybridization and analysis}

For transcript profiling, S. cerevisiae microarrays were used, which were synthesized in duplicate on glass by Microarray Center of University Health Network (Canada), comprising 6,240 yeast ORFs. Microarrays were prehybridized for $45 \mathrm{~min}$ at $42^{\circ} \mathrm{C}$ in $3 \times \mathrm{SSC}$ $(0.15 \mathrm{M} \mathrm{NaCl}$ and $0.015 \mathrm{M}$ sodium citrate), $0.1 \%(\mathrm{w} / \mathrm{v})$ SDS and $0.1 \mathrm{mg} / \mathrm{ml}$ BSA. Prehybridized microarrays were washed twice with water, once with isopropanol and then dried by centrifugation. Before hybridization, equal quantities of Cy5- and Cy3-labelled cDNA, 50\% (v/v) formamide, $5 \times$ SSC and $0.1 \%(\mathrm{w} / \mathrm{v})$ SDS were mixed, made up to a final volume of $60 \mu \mathrm{l}$ with water and denatured for $1 \mathrm{~min}$ at $95^{\circ} \mathrm{C}$. The mixture was applied to the prehybridized microarrays, covered with a Hybri-slip (60 x $24 \mathrm{~mm}$; Sigma-Aldrich) and hybridization took place for 16 hours in a humidified chamber in a water bath at $42^{\circ} \mathrm{C}$. Hybridized microarrays were washed for $5 \mathrm{~min}$ at $42^{\circ} \mathrm{C}$ in $2 \times \mathrm{SSC}, 0.1 \%(\mathrm{w} / \mathrm{v})$ $\mathrm{SDS}$, for $20 \mathrm{~min}$ at room temperatures in $0.1 \mathrm{x} \mathrm{SSC}$, $0.1 \%(\mathrm{w} / \mathrm{v}) \mathrm{SDS}$, for $6 \mathrm{~min}$ at room temperatures in $0.1 \mathrm{x}$ $\mathrm{SSC}$, and for $1 \mathrm{~min}$ at room temperatures in $0.01 \mathrm{x}$ SSC. Hybridized microarrays were dried by centrifugation. After washing, the microarrays were immediately 
scanned with an Axon 4100A scanner at a resolution of $10 \mu \mathrm{m}$ and data were analyzed using the GenePix Pro 6.1 software package (Axon Instruments). Hybridization specificity was assured because no signal was observed in control spots with bacterial or plants unspecific DNA. Data were ratio-based normalized and processed using Acuity 4.0 (Axon Instruments). False Discovery Rate (FDR) of $5 \%$ was used to identify statistically significant data. A cut-off rate of $>2$-fold was used to select for induced genes. Functional group analysis was done using GOstat, DAVID Database and GO term finder (SGD database) online applications selecting for Bonferroni corrected $p$-values $<0.05$. mRNA level of selected genes was confirmed by qRT-PCR. The microarray transcriptomic data presented correspond to the average of three biological replicates (separate cultures on different days) including a dye swap. The microarray data was deposited in ArrayExpress database with the accession number ETABM-1131.

\section{qRT-PCR}

To validate microarrays results, amplified RNA was converted to cDNA and mRNA level of seven genes, in different strains and conditions, was quantified by qRTPCR. $1 \mu \mathrm{g}$ of RNA was mixed with $0.5 \mathrm{mM}$ dNTPs, 50 pmol Oligo(dT) in $10 \mu \mathrm{l}$. The mix was heated to $65^{\circ} \mathrm{C}$ for $5 \mathrm{~min}$ and chilled on ice. Then $10 \mathrm{mM}$ DTT, 50U RNAse inhibitor (Invitrogen), 1x First Strand Buffer (Invitrogen) and water to $20 \mu \mathrm{l}$ were added to the mix and it was incubated $2 \mathrm{~min}$ at room temp. After adding 500 U Superscript III (Invitrogen), samples were incubated at $42^{\circ} \mathrm{C}$ for $50 \mathrm{~min}$ and reaction was inactivated $15 \mathrm{~min}$ at $70^{\circ} \mathrm{C}$. Agarose gel electrophoresis was done to check nucleic acid contaminations. qRT-PCR was performed with gene-specific primers (200 nM) (Additional file 1: Table S6) in a $20 \mu$ reaction, using the Light Cycler Fast Start DNA Master PLUS SYBR green (Roche Applied Science, Germany) in a LightCycler ${ }^{\circledR} 2.0$ System (Roche Applied Science, Germany) device. All samples were processed for melting curve analysis, amplification efficiency and DNA concentration determination using LightCycler $^{\circledR} 2.0$ System. A mix of all samples and serial dilutions $\left(10^{-1}\right.$ to $\left.10^{-5}\right)$ were used as standard curve.

\section{Survival during oxidative stress}

Strains were grown overnight in YPD at $30^{\circ} \mathrm{C}$. After adjusting to $1 \times 10^{6}$ cells/ml in PBS, $6 \mathrm{mM} \mathrm{H}_{2} \mathrm{O}_{2}$ (Panreac) were added and samples were incubated for one hour at $30^{\circ} \mathrm{C}$ with shaking. Dilutions $10^{-2}$ to $10^{-4}$ were done and $100 \mu \mathrm{l}$ from these dilutions were spread on YPD plates, incubated for $48 \mathrm{~h}$ at $30^{\circ} \mathrm{C}$ and cfu were counted. Survival was calculated as the ratio of treated over untreated cells (time point $0 \mathrm{~min}$ ). To compare resistance to oxidative stress of D14, D14YAP1 and
D14 $\triangle$ Yap1 strains cells were patched on YPD or YPD with $2.5 \mathrm{mM} \mathrm{H}_{2} \mathrm{O}_{2}$ plates and let them grow for $48 \mathrm{~h}$. Each strain was tested at least in three independent experiments. Data are represented as averages \pm standard error and statistical significance was determined using Student's $t$ test (see Additional file 1: Table S5).

\section{Survival assay in human blood}

To investigate the survival of yeast strains in blood, $C$. albicans SC5314 and four $S$. cerevisiae strains were assayed. Yeast strains were grown overnight in YPD medium at $30^{\circ} \mathrm{C}$. The cells were washed once and suspended in PBS buffer (Phosphate-buffered saline: $150 \mathrm{mM} \mathrm{NaCl}, 16 \mathrm{mM} \mathrm{Na}_{2} \mathrm{HPO}_{4}, 4 \mathrm{mM} \mathrm{NaH}{ }_{2} \mathrm{PO}_{4}, \mathrm{pH}$ 7.4) at a density of $5 \times 10^{7}$ cells/ml. Human peripheral venous blood was collected from healthy volunteers by venipuncture using ammonium heparin syringes (Monovette $^{\circledR}$, Sarstedt). Yeast cells were inoculated (1:1 ratio of yeast: leukocytes) in blood and incubated for 10 and $60 \mathrm{~min}$ at $37^{\circ} \mathrm{C}$. At each time point, $100 \mu \mathrm{l}$ of $10^{-2}$ to $10^{-4}$ dilutions were spread on YPD plates and incubated for $48 \mathrm{~h}$ at $30^{\circ} \mathrm{C}$. Colony-forming units (cfu) were counted and percentages of survival determined as follows: (cfu/ $\left.\mathrm{cfu}_{\text {plasma }}\right) \mathrm{x}$ 100. Each strain was tested three times. Data were represented as averages \pm standard error.

\section{Additional files}

Additional file 1: Table S1. Genes and statistical significance ( $p$-values) of the functional groups expressed at 15, 30 and 60 min of incubation in blood in virulent strains (60 and D14) and non-virulent (CECT 10.431 and W303). Table S2. Genes and statistical significance ( $p$ values) of the functional groups repressed at 30 min of incubation in blood in virulent strains (60 and D14) and non-virulent (CECT 10431 and W303). Table S4. qRT-PCR validation of transcriptomic data. Table S5. Statistical pairwise comparisons of Figure 2. Table 6. Primers used in this study.

Additional file 2: Table S3. Complete microarray dataset.

\section{Competing interests}

The authors declare that they have no competing interests.

\section{Authors' contributions}

SLI carried out transcriptomics experiments and data analysis, blood survival assays and drafted the manuscript. RPT carried out transcriptomics experiments and data analysis, blood survival assays, oxidative stress assays and mutant construction. AH helped with blood survival assays. BH supervised blood survival assays and corrected the manuscript. L participated in the design of the study and supported the study. AQ and MTFE participated in the design of the study and corrected the manuscript. RPT conceived the study and participated in the design of the study and drafted the manuscript. All authors read and approved the final manuscript.

\section{Acknowledgements}

S. Llopis was recipient of a FPU fellowship from the Ministerio de Educación y Ciencia, Spain. R. Pérez-Torrado was supported from JAEDOC postdoctoral program (CSIC). This work was supported by CICYT grant (ref. AGL200612710-CO2-01 and 02) from Ministerio de Educación y Ciencia and by grant PROMETEO (project PROMETEO/2009/019) from Generalitat Valenciana. 


\section{Author details}

${ }^{1}$ Instituto de Agroquímica y Tecnología de los Alimentos, IATA-CSIC, P.O. Box 73. E-46100, Burjassot, Spain. ²Department of Microbial Pathogenicity Mechanisms, Leibniz Institute for Natural Product Research and Infection Biology, Hans-Knoell-Institute (HKI), Jena, Germany. ${ }^{3}$ Friedrich Schiller University, Jena, Germany. ${ }^{4}$ Department of Food Science, Food Microbiology, Faculty of Life Sciences, University of Copenhagen, Copenhagen, Denmark.

Received: 4 April 2012 Accepted: 20 August 2012

Published: 23 August 2012

\section{References}

1. Enache-Angoulvant A, Hennequin C: Invasive Saccharomyces infection: a comprehensive review. Clin Infect Dis 2005, 41:1559-1568.

2. Muñoz P, Bouza E, Cuenca-Estrella M, Eiros JM, Perez MJ, Sanchez-Somolinos M, Rincon C, Hortal J, Pelaez T: Saccharomyces cerevisiae fungemia: an emerging infectious disease. Clin Infect Dis 2005, 40:1625-1634.

3. de Llanos R, Llopis S, Molero G, Querol A, Gil C, Fernandez-Espinar MT: In vivo virulence of commercial Saccharomyces cerevisiae strains with pathogenicity-associated phenotypical traits. Int J Food Microbiol 2011, 144:393-399.

4. Jensen DP, Smith DL: Fever of unknown origin secondary to brewer's yeast ingestion. Arch Intern Med 1976, 136:332-333.

5. Smith D, Metzgar D, Wills C, Fierer J: Fatal Saccharomyces cerevisiae aortic graft infection. J Clin Microbiol 2002, 40:2691-2692.

6. Herbrecht R, Nivoix Y: Saccharomyces cerevisiae fungemia: an adverse effect of Saccharomyces boulardii probiotic administration. Clin Infect Dis 2005, 40:1635-1637.

7. de Llanos R, Fernandez-Espinar MT, Querol A: A comparison of clinical and food Saccharomyces cerevisiae isolates on the basis of potential virulence factors. Antonie Van Leeuwenhoek 2006, 90:221-231.

8. Swinne D, Nolard N, Van RP, Detandt M: Bloodstream yeast infections: a 15-month survey. Epidemiol Infect 2009, 137:1037-1040.

9. Lherm T, Monet C, Nougiere B, Soulier M, Larbi D, Le GC, Caen D, Malbrunot C: Seven cases of fungemia with Saccharomyces boulardii in critically ill patients. Intensive Care Med 2002, 28:797-801.

10. Cassone M, Serra P, Mondello F, Girolamo A, Scafetti S, Pistella E, Venditti M: Outbreak of Saccharomyces cerevisiae subtype boulardii fungemia in patients neighboring those treated with a probiotic preparation of the organism. J Clin Microbiol 2003, 41:5340-5343.

11. Graf C, Gavazzi G: Saccharomyces cerevisiae fungemia in an immunocompromised patient not treated with Saccharomyces boulardil preparation. J Infect 2007, 54:310-311.

12. Calderone RA: Candida and candidiasis. 2nd edition. New York: American Society for Microbiology; 2002.

13. Zelante T, Montagnoli C, Bozza S, Gaziano R, Bellocchio S, Bonifazi P, Moretti S, Fallarino F, Puccetti P, Romani L: Receptors and pathways in innate antifungal immunity: the implication for tolerance and immunity to fungi. Adv Exp Med Biol 2007, 590:209-221.

14. McCusker JH, Clemons KV, Stevens DA, Davis RW: Genetic characterization of pathogenic Saccharomyces cerevisiae isolates. Genetics 1994, 136:1261-1269.

15. McCusker JH, Clemons KV, Stevens DA, Davis RW: Saccharomyces cerevisiae virulence phenotype as determined with CD-1 mice is associated with the ability to grow at 42 degrees $C$ and form pseudohyphae. Infect Immun 1994, 62:5447-5455.

16. Clemons KV, Hanson LC, Stevens DA: Colony phenotype switching in clinical and non-clinical isolates of Saccharomyces cerevisiae. J Med Vet Mycol 1996, 34:259-264.

17. Klingberg TD, Lesnik U, Arneborg N, Raspor P, Jespersen L: Comparison of Saccharomyces cerevisiae strains of clinical and nonclinical origin by molecular typing and determination of putative virulence traits. FEMS Yeast Res 2008, 8:631-640.

18. Yañez A, Murciano C, Llopis S, Fernández-Espinar T, Gil ML, Gozalbo D: In vivo and in vitro studies on virulence and host responses to Saccharomyces cerevisiae clinical and non-clinical isolates. The Open Mycology Journal 2009, 3:37-47

19. Fradin C, Kretschmar M, Nichterlein T, Gaillardin C: d'Enfert C, Hube B: Stage-specific gene expression of Candida albicans in human blood. Mol Microbiol 2003, 47:1523-1543

20. Fradin C, De GP, MacCallum D, Schaller M, Klis F, Odds FC, Hube B: Granulocytes govern the transcriptional response, morphology and proliferation of Candida albicans in human blood. Mol Microbiol 2005, 56:397-415.

21. Becker J, Craig EA: Heat-shock proteins as molecular chaperones. Eur J Biochem 1994, 219:11-23.

22. Memisoglu A, Samson L: Base excision repair in yeast and mammals. Mutat Res 2000, 451:39-51.

23. Abshire KZ, Neidhardt FC: Analysis of proteins synthesized by Salmonella typhimurium during growth within a host macrophage. J Bacteriol 1993, 175:3734-3743.

24. Rea RB, Gahan CG, Hill C: Disruption of putative regulatory loci in Listeria monocytogenes demonstrates a significant role for Fur and PerR in virulence. Infect Immun 2004, 72:717-727.

25. Riboulet E, Verneuil N, La CS, Sauvageot N, Auffray Y, Hartke A, Giard JC: Relationships between oxidative stress response and virulence in Enterococcus faecalis. J Mol Microbiol Biotechnol 2007, 13:140-146.

26. Rubin-Bejerano I, Fraser I, Grisafi P, Fink GR: Phagocytosis by neutrophils induces an amino acid deprivation response in Saccharomyces cerevisiae and Candida albicans. Proc Natl Acad Sci USA 2003, 100:11007-11012.

27. Lorenz MC, Fink GR: The glyoxylate cycle is required for fungal virulence. Nature 2001, 412:83-86.

28. Kingsbury JM, Goldstein AL, McCusker JH: Role of nitrogen and carbon transport, regulation, and metabolism genes for Saccharomyces cerevisiae survival in vivo. Eukaryot Cell 2006, 5:816-824.

29. Padilla PA, Fuge EK, Crawford ME, Errett A, Werner-Washburne M: The highly conserved, coregulated SNO and SNZ gene families in Saccharomyces cerevisiae respond to nutrient limitation. J Bacterio/ 1998, 180:5718-5726.

30. McKinney JD: Honer zu BK, Munoz-Elias EJ, Miczak A, Chen B, Chan WT, Swenson D, Sacchettini JC, Jacobs WR Jr, Russell DG: Persistence of Mycobacterium tuberculosis in macrophages and mice requires the glyoxylate shunt enzyme isocitrate lyase. Nature 2000, 406:735-738.

31. Rude TH, Toffaletti DL, Cox GM, Perfect JR: Relationship of the glyoxylate pathway to the pathogenesis of Cryptococcus neoformans. Infect Immun 2002, 70:5684-5694.

32. Idnurm A, Howlett BJ: Isocitrate lyase is essential for pathogenicity of the fungus Leptosphaeria maculans to canola (Brassica napus). Eukaryot Cell 2002, 1:719-724

33. Goldstein AL, McCusker JH: Development of Saccharomyces cerevisiae as a model pathogen A system for the genetic identification of gene products required for survival in the mammalian host environment. Genetics 2001, 159:499-513.

34. Lorenz MC, Bender JA, Fink GR: Transcriptional response of Candida albicans upon internalization by macrophages. Eukaryot Cell 2004, 3:1076-1087.

35. Diezmann S, Dietrich FS: Saccharomyces cerevisiae: population divergence and resistance to oxidative stress in clinical, domesticated and wild isolates. Plos One 2009, 4:e5317.

36. Bogdan C, Rollinghoff $M$, Diefenbach A: Reactive oxygen and reactive nitrogen intermediates in innate and specific immunity. Curr Opin Immunol 2000, 12:64-76.

37. Brown AJ, Haynes K, Quinn J: Nitrosative and oxidative stress responses in fungal pathogenicity. Curr Opin Microbiol 2009, 12:384-391.

38. Rodrigues-Pousada C, Menezes RA, Pimentel C: The Yap family and its role in stress response. Yeast 2010, 27:245-258.

39. Lushchak OV, Inoue Y, Lushchak VI: Regulatory protein Yap1 is involved in response of yeast Saccharomyces cerevisiae to nitrosative stress. Biochemistry (Mosc) 2010, 75:629-664

40. Zakikhany K, Naglik JR, Schmidt-Westhausen A, Holland G, Schaller M, Hube B: In vivo transcript profiling of Candida albicans identifies a gene essential for interepithelial dissemination. Cell Microbiol 2007, 9:2938-2954.

41. Missall TA, Lodge JK: Function of the thioredoxin proteins in Cryptococcus neoformans during stress or virulence and regulation by putative transcriptional modulators. Mol Microbiol 2005, 57:847-858,

42. Wright WL, Wenzel RP: Nosocomial Candida Epidemiology, transmission, and prevention. Infect Dis Clin North Am 1997, 11:411-425.

43. Bodey G, Bueltmann B, Duguid W, Gibbs D, Hanak H, Hotchi M, Mall G, Martino P, Meunier F, Milliken S, et al: Fungal infections in cancer patients: an international autopsy survey. Eur J Clin Microbiol Infect Dis 1992, 11:99-109. 
44. Güldener U, Heck S, Fiedler T, Beinhauer J, Hegemann JH: A new efficient gene disruption cassette for repeated use in budding yeast. Nucleic Acids Res 1996, 13:2519-2524.

45. Goldstein AL, McCusker JH: Three new dominant drug resistance cassettes for gene disruption in Saccharomyces cerevisiae. Yeast 1999, 15:1541-15.

46. Kuge S, Jones N, Nomoto A: Regulation of yAP-1 nuclear localization in response to oxidative stress. EMBO J 1997, 16:1710-1720.

47. Ausubel FM, Brent B, Kingston RE, Moore DD, Seidman JG, Smith JA, Struhl K: Current protocols in molecular biology. Edison, NJ: John Wiley \& Sons; 2000.

doi:10.1186/1471-2164-13-419

Cite this article as: Llopis et al:: Transcriptomics in human blood incubation reveals the importance of oxidative stress response in Saccharomyces cerevisiae clinical strains. BMC Genomics 2012 13:419.

\section{Submit your next manuscript to BioMed Central and take full advantage of:}

- Convenient online submission

- Thorough peer review

- No space constraints or color figure charges

- Immediate publication on acceptance

- Inclusion in PubMed, CAS, Scopus and Google Scholar

- Research which is freely available for redistribution 